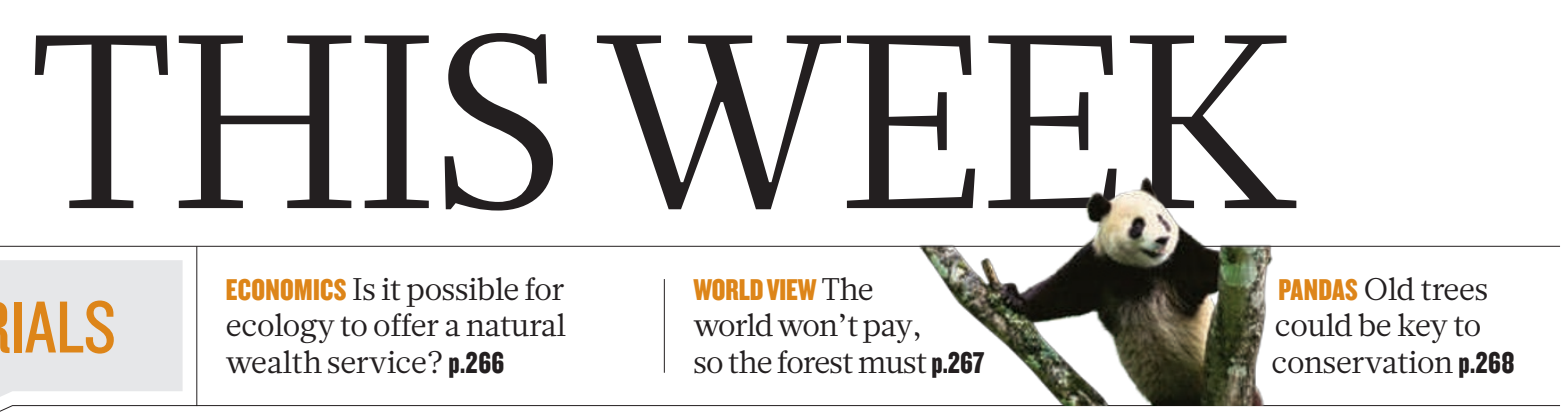

\title{
Smallpox should be saved
}

\author{
Secure virus stocks in the United States and Russia may still prove useful and should not be \\ destroyed. A political compromise is the best way to make that happen.
}

$\mathrm{F}$ Ior much of the world's population, smallpox is a disease of history. The variola virus that causes it last swept through humans in a natural outbreak in Somalia in 1977, and the world was declared free of smallpox in 1980. The disease that killed Queen Mary II of England, Tsar Peter II of Russia, King Louis XV of France and hundreds of millions more during the past century alone is gone - but not forgotten. Smallpox lives on in the memories of those who witnessed its awful impact first hand. It is a terrifying spectre for those who warn that terrorists may seek to spread disease. And it survives in two laboratories, where research continues on live virus.

The fate of these known virus stocks, held in secure laboratories in the United States and Russia, is once again the subject of debate. In May 2011, the World Health Assembly - the decision-making body of the World Health Organization - will vote on whether to set a date by which these collections should be destroyed. They should not be eliminated, at least not completely.

This journal has previously argued that, because the possibility cannot be ruled out that other, secret stocks of smallpox are being held elsewhere, the benefits of continued access to live virus stocks for research outweigh the risks of maintaining them. In 1999 (Nature 398,733 ; 1999), we wrote: "Rightly, public-health advocates bemoan the prospect of any measure that increases the risk of a re-emergence of this scourge. But, given the impossibility of knowing who now possesses the virus, and from where it might appear, it is better to have a number of arrows in the quiver than to destroy the stock and cross our collective fingers." The world has changed much since then, and the US terrorist attacks of September 2001 and the subsequent focus on prospects for bioterrorism have increased the stakes further. Smallpox would be an effective weapon - it spreads easily and kills almost one-third of the people it infects. Furthermore, the triumph of smallpox eradication after widespread vaccination in the 1960s and 1970s means that some $40 \%$ of the world's population has no immunity.

In an essay published online earlier this month in the journal Biosecurity and Bioterrorism: Biodefense Strategy, Practice, and Science, security expert Jonathan Tucker argues that many of the stated goals of the World Health Organization's smallpox research programme have been achieved - such as antiviral drugs and diagnostic tools - and that there is a diminished need for live virus to be retained (J. B. Tucker Biosecur. Bioterror. doi:10.1089/bsp.2010.0065; 2011). This may be true, but further study of the virus could still reveal a huge amount, both on the specifics of what makes it such a formidable foe and on human immunology and viral pathogenesis in general.

The scientific case for retaining live variola virus to improve public health is strong. The risk of doing so is largely political. The threat of an accidental release or theft from the biosecure repositories at which it is held - at the Centers for Disease Control and Prevention in Atlanta, Georgia, and the State Research Center of Virology and Biotechnology ('Vector') near Novosibirsk - seems remote.
Destruction of the stocks would be a largely symbolic step.

Countries in Africa and Asia endured the havoc of smallpox most recently, and fear of a repeat outbreak - as well as mistrust of those who control the stocks - has produced strong calls from these nations for its destruction. There is equally strong insistence in countries such as the United States and Russia that it should be retained for defensive research. In a recent article in The New York Times, former US government
"Smallpox is a disease of history, but it cannot be consigned to the past."

Tucker warns that the result of this political stand-off, further complicated by the rare involvement of security and defence officials in a publichealth matter, could be a "diplomatic train wreck" - particularly given that the World Health Assembly will seek a consensus decision. As part of a compromise solution, he suggests that the United States and Russia should agree to destroy part of their collections, such as hybrid viruses that are scientifically redundant. A handful of strains would continue to be held at each site, for research in the short term and reference afterwards. That seems a sensible approach. True, the world will be denied a final victory in the heroic effort to defeat smallpox, but uncertainty over undeclared surviving stocks would make that a hollow accomplishment anyway. So, too, would development of molecular-biology techniques that could see the smallpox virus reconstructed. Smallpox is a disease of history, but it cannot be consigned to the past.

\section{Goodbye Tevatron}

\section{The decision to shut down the ageing particle collider at Fermilab is the right one.}

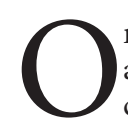
n 10 January, the US Department of Energy (DOE) announced that the United States will close its only particle collider, the Tevatron, located at Fermilab in Batavia, Illinois. The decision to shutter the decades-old collider this year (see Nature 469,141 ; 2011) goes against the recommendations of the US particle-physics community's scientific advisory group, which believes that the machine still has work to do. But given the financial constraints facing Fermilab, and its ambitions for the future, the choice is at once courageous and correct. Moreover, it should serve as an example to other scientific communities that are clinging to ageing 